\title{
Streptococcus orisuis sp. nov., isolated from the pig oral cavity
}

\author{
Kazuko Takada and Masatomo Hirasawa \\ Department of Microbiology and Immunology, Nihon University School of Dentistry at Matsudo, \\ 2-870-1 Sakaecho-nishi, Matsudo, Chiba 271-8587, Japan
}

Correspondence

Masatomo Hirasawa

hirasawa.masatomo@

nihon-u.ac.jp
The mutans streptococci, comprising seven species and eight different serotypes, are generally accepted as the main bacterial causes of dental caries. Streptococcus mutans (serotypes $c, e$ and $f$ ) and Streptococcus sobrinus (serotypes $d$ and $g$ ) are most commonly isolated from human dental plaque, Streptococcus criceti (serotype $a$ ) has been isolated from hamsters, Streptococcus ratti (serotype b) and Streptococcus ferus (serotype $c$ ) have been isolated from rats and Streptococcus downei (serotype $h$ ) and Streptococcus macacae (serotype $c$ ) have been isolated from monkeys (Beighton et al., 1981; Hamada \& Slade, 1980; Whiley et al., 1988). Recently, a novel species displaying close affinity with mutans streptococci from equine teeth was reported (Collins et al., 2004). The colonization of the oral cavity by mutans streptococci is assumed to be caused by sucrose intake. As pigs are omnivorous animals, they often have the opportunity to ingest sucrose. We investigated the microflora of the porcine oral cavity, focusing on mutans streptococci.

To investigate the oral microflora of pigs, a group of Gram-positive cocci were characterized. Mitis salivarius agar (Difco) is widely used to isolate $S$. mutans as well as other oral streptococcal species. The five mutans streptococcus-like strains selected for this study were randomly chosen from among 117 streptococcal isolates obtained on mitis salivarius agar from the oral cavities of 39 pigs (from two different farms). The strains formed small, raised, adherent colonies with irregular margins. The strains were grown at $37^{\circ} \mathrm{C}$ under anaerobic conditions on brain-heart infusion agar (Difco) supplemented with $5 \%$ horse blood. A biochemical analysis was conducted using the Rapid ID32 Strep, API $50 \mathrm{CH}$ and API ZYM (bioMérieux) and Streptogram (Wako) systems according to the manufacturers'

The GenBank/EMBL/DDBJ accession number for the $16 \mathrm{~S}$ rRNA gene sequence of strain NUM $1001^{\top}$ is AB182324. instructions. The colonial formation and biochemical characteristics resembled those of mutans streptococci. Isolates NUM $1001^{\mathrm{T}}$, NUM 1002, NUM 1003, NUM 1004 and NUM 1005 were subjected to further taxonomic study.

DNA was extracted from bacterial cultures by using the Promega Genome kit according to the manufacturer's instructions. The $\mathrm{G}+\mathrm{C}$ contents of the DNAs were determined by HPLC using a method described previously (Hirasawa \& Takada, 1994). The DNA G + C contents of strains NUM $1001^{\mathrm{T}}$, NUM 1002, NUM 1003, NUM 1004 and NUM 1005 ranged from 42 to $44 \mathrm{~mol} \%$, which is similar to that for S. criceti. DNA-DNA hybridization was performed according to the microtitration plate method (Ezaki et al., 1989), with minor modifications. A heatdenatured sample of DNA $(1 \mu \mathrm{g})$ was immobilized in each well of a microplate (Immuno plate II; Nunc) at $30^{\circ} \mathrm{C}$ for $2 \mathrm{~h}$. The microplate was dried at $45^{\circ} \mathrm{C}$ for $2 \mathrm{~h}$ and then photobiotin-labelled heat-denatured probe DNA $(0.125 \mu \mathrm{g}$ per well) was used for the hybridization (incubated at $42.5^{\circ} \mathrm{C}$ for $3 \mathrm{~h}$ ). Other procedures were conducted according to the original instructions. Levels of DNA-DNA hybridization were examined using labelled DNA from strain NUM $1001^{\mathrm{T}}$ and $S$. criceti ATCC $19642^{\mathrm{T}}$ against other strains of mutans streptococci. There were very high levels of hybridization among the five isolates and between $S$. criceti strains ATCC $19642^{\mathrm{T}}$ and OMZ 61 relative to each labelled strain, confirming a relationship at the species level. The highest level of DNA-DNA hybridization was found with $S$. criceti ATCC $19642^{\mathrm{T}}$, but the level of relatedness was only 42.5-58.1\%. DNAs from strains of mutans streptococci, namely S. downei NCTC $11391^{\mathrm{T}}$, S. sobrinus NIDR6715, S. ratti ATCC $19645^{\mathrm{T}}$ and $S$. mutans JC2, exhibited relatedness levels of $21.4,12.8,7.4$ and $7.2 \%$, respectively, to strain NUM $1001^{\mathrm{T}}$. To determine the phylogenetic affinity of each of the clinical isolates, the almost-complete 16S rRNA gene 


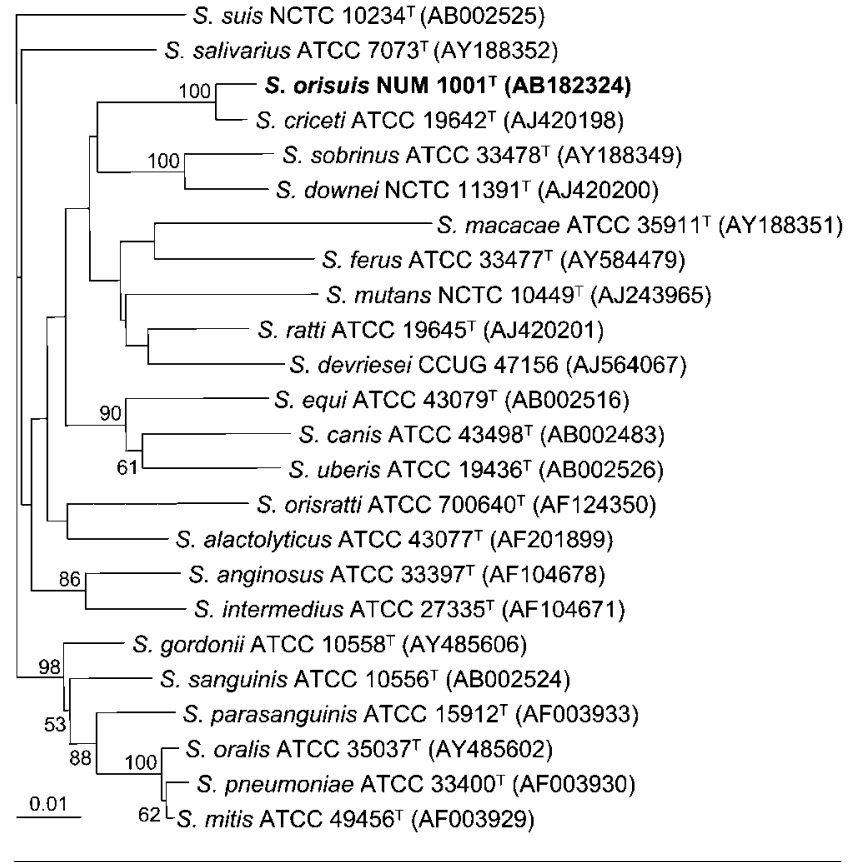

Fig. 1. Neighbour-joining phylogenetic tree, derived from $16 \mathrm{~S}$ rRNA gene sequences, showing the position of strain NUM $1001^{\top}$ with respect to members of the genus Streptococcus. The tree is based on a comparison of approximately $1330 \mathrm{nt}$. Bootstrap percentages (based on 1000 replicates), where greater than $50 \%$, are shown at branch points. Bar, 0.01 substitutions per nucleotide position.

was sequenced and subjected to a comparative analysis. The $16 \mathrm{~S}$ rRNA gene was amplified by using a PCR with primers 27f (5'-AGAGTTTGATCCTGGCTCAG-3'; Escherichia coli positions 8-27) and 1525r (5'-AAAGGAGGTGATCCAGCC-3'; E. coli positions 1543-1525) according to the method described by Shinoda et al. (2000). The PCR products were purified with a Mini Elute gel extraction kit (Qiagen) and directly sequenced using a BigDye Terminator v1.1 cycle sequencing kit (Applied Biosystems) and an automatic DNA sequencer (ABI PRISM, model 373A; Applied Biosystems) by Takara Bio (Mie, Japan). The closest known relatives of the novel isolates were identified by performing database searches. Their 16S rRNA gene sequences were compared with those available in the DNA Data Bank of Japan (Mishima, Japan) using BLAST software. Nucleotide substitution rates ( $K_{\text {nuc }}$ values) were calculated (Kimura, 1980) and phylogenetic trees were constructed by using the neighbour-joining method (Saitou \& Nei, 1987). The topologies of the trees were evaluated by performing a bootstrap analysis of the sequence data, using CLUSTAL W software (Thompson et al., 1994). Sequence similarity values were calculated manually. The highest levels of $16 \mathrm{~S}$ rRNA gene sequence similarity to strain NUM $1001^{\mathrm{T}}$ were obtained with S. criceti ATCC $19642^{\mathrm{T}}$ and S. downei NCTC $11391^{\mathrm{T}}$ (97.8 and $94.1 \%$, respectively). Despite the relatively high levels of sequence similarity among $S$. criceti ATCC $19642^{\mathrm{T}}$, S. downei NCTC $11391^{\mathrm{T}}$ and NUM $1001^{\mathrm{T}}$ compared with the levels of similarity among representatives of the other species within the mutans streptococci, the results show that the pig strains are sufficiently dissimilar from $S$. criceti and $S$. downei to warrant separate species status. A tree constructed by neighbour-joining, depicting the phylogenetic affinity of strain NUM $1001^{\mathrm{T}}$ with members of the genus Streptococcus, is shown in Fig. 1.

Serotypes were determined with an agar-gel immunodiffusion test using rabbit antisera raised against reference strains prepared as described previously (Hirasawa et al., 1980; Takada et al., 1984). Rantz-Randle extract antigens were prepared from cells cultured overnight on brain-heart infusion agar as described previously. Fig. 2 shows the double immunodiffusion patterns obtained with the Rantz-Randle extract antigens and various antibodies. In immunodiffusion experiments with strain NUM $1001^{\mathrm{T}}$, cross-reactive precipitin bands were formed with typing
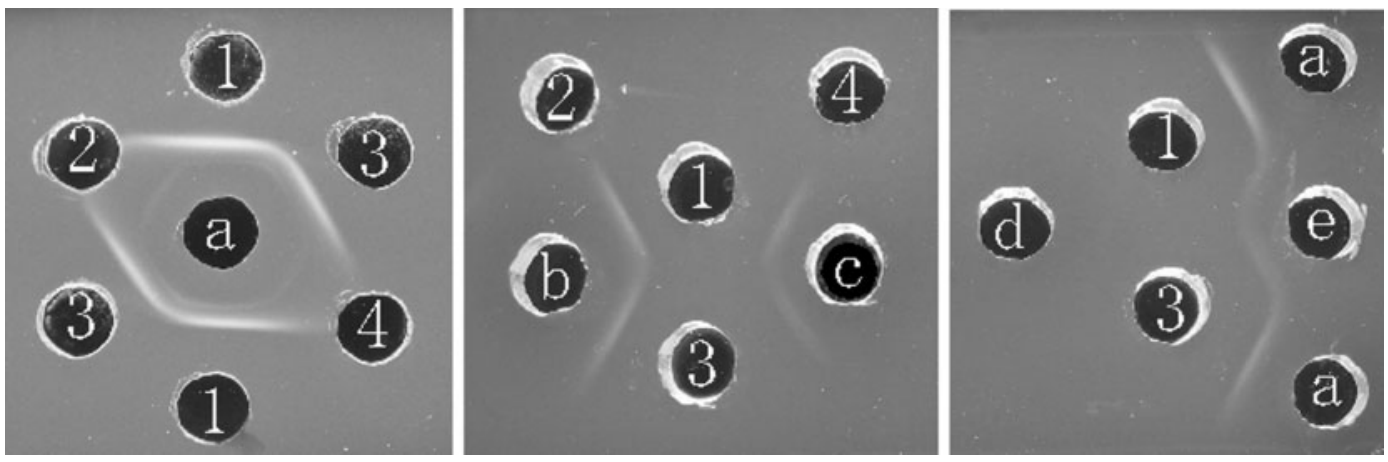

Fig. 2. Double immunodiffusion analyses of antigen preparations with various antisera. Wells designated $a, b, c, d$ and $e$ contain anti-NUM $1001^{\top}$ serum, anti-NUM $1001^{\top}$ absorbed with cells of S. criceti HS-6 (serotype a) serum, anti-NUM $1001^{\top}$ absorbed with cells of S. sobrinus NIDR6715 ( $g$ ) serum, anti-NUM $1001^{\top}$ absorbed with cells of S. sobrinus OMZ-176 (d) serum and anti-OMZ-176 serum, respectively. Antigens designated 1, 2, 3 and 4 were extracted from cells of NUM $1001^{\top}$, HS-6, OMZ-176 and NIDR6715, respectively. 
Table 1. Characteristics that differentiate species within the mutans streptococci

Taxa: 1, strain NUM $1001^{\mathrm{T}}$ (S. orisuis sp. nov.); 2, S. mutans; 3, S. ferus; 4, S. criceti; 5, S. sobrinus; 6, S. ratti; 7, S. downei; 8, S. macacae. Data are from Whiley \& Beighton (1998) and this study. All of the taxa are positive for fermentation of mannitol and for production of insoluble glucan from sucrose and all give positive results in the Voges-Proskauer test.

\begin{tabular}{|c|c|c|c|c|c|c|c|c|}
\hline Characteristic & 1 & 2 & 3 & 4 & 5 & 6 & 7 & 8 \\
\hline \multicolumn{9}{|l|}{ Fermentation of: } \\
\hline Sorbitol & + & + & + & + & + & + & - & + \\
\hline Melibiose & + & + & - & + & - & + & - & - \\
\hline Raffinose & + & + & - & + & + & + & - & + \\
\hline \multicolumn{9}{|l|}{ Hydrolysis of: } \\
\hline Arginine & - & - & - & - & - & + & - & - \\
\hline Aesculin & + & + & - & + & + & + & - & - \\
\hline Inulin & + & + & + & + & - & + & + & - \\
\hline Resistance to bacitracin $\left(2 \mathrm{U} \mathrm{ml}^{-1}\right)$ & - & + & - & - & + & + & - & - \\
\hline Serovar(s) & $d$ & $c, e, f$ & $c$ & $a$ & $d, g$ & $b$ & $h$ & $c$ \\
\hline DNA G $+\mathrm{C}$ content $(\mathrm{mol} \%)$ & $42-44$ & $36-38$ & $43-45$ & $42-44$ & $44-46$ & $41-43$ & $41-42$ & $35-36$ \\
\hline Source(s) of isolation & Pig & Human & Wild rat & $\begin{array}{l}\text { Hamster, } \\
\text { human, } \\
\text { wild rat }\end{array}$ & Human & Rat, human & Monkey & Monkey \\
\hline
\end{tabular}

sera prepared against mutans streptococci strains of serotype $a, d$ or $g$ (Fig. 2, left panel) but not $c, e$ or $f$. The specific antiserum obtained by absorbing antiserum raised against novel isolate NUM $1001^{\mathrm{T}}$ with cells of serotype $a$ and $g$ reacted with NUM $1001^{\mathrm{T}}$ and a serotype $d$ strain (Fig. 2, centre panel). The antiserum raised against NUM $1001^{\mathrm{T}}$ or serotype $d$ cells reacted identically with NUM $1001^{\mathrm{T}}$ and serotype $d$ (Fig. 2, right panel). The antiserum obtained by absorbing antiserum raised against NUM $1001^{\mathrm{T}}$ with cells of serotype $d$ did not react with NUM $1001^{\mathrm{T}}$. These results suggest that isolate NUM $1001^{\mathrm{T}}$ should be grouped within serotype $d$.

Strain NUM $1001^{\mathrm{T}}$ isolated from the porcine oral cavity is serologically unique. Biochemically, too, it is readily distinguishable from all other previously described mutans streptococci (Hamada \& Slade, 1980). The phenotypic characteristics that differentiate strain NUM $1001^{\mathrm{T}}$ from other mutans streptococci are shown in Table 1. Therefore, on the basis of the distinct phenotypic characteristics and biochemical and molecular genetic data obtained in this study, strain NUM $1001^{\mathrm{T}}$ warrants classification within a novel species of the genus Streptococcus, and a member of the mutans streptococci, for which the name Streptococcus orisuis sp. nov. is proposed.

\section{Description of Streptococcus orisuis sp. nov.}

Streptococcus orisuis (o.ri.su' is. L. gen. n. oris of the mouth; L. gen. n. suis of a pig; N.L. gen. n. orisuis from/of the mouth of a pig).

Cells are Gram-positive, non-spore-forming cocci, 0.5$0.75 \mu \mathrm{m}$ in diameter, that occur in pairs or in short chains.
Colonies on blood agar are small and white, $0.75-1.0 \mathrm{~mm}$ in diameter and non-haemolytic at $37^{\circ} \mathrm{C}$. On mitis salivarius agar, colonies are small, dark blue and crinkled. Facultatively anaerobic and catalase-negative. No Lancefield carbohydrate antigens (streptococcal grouping kit; Oxoid) are detected. According to API systems, strains produce acid from D-glucose, galactose, D-fructose, D-mannose, mannitol, sorbitol, $N$-acetylglucosamine, amygdalin, arbutin, aesculin, salicin, cellobiose, maltose, lactose, melibiose, sucrose, trehalose, inulin, D-raffinose, $\beta$-gentiobiose, methyl $\beta$-D-glucopyranoside and D-tagatose. Alanine phenylalanine proline arylamidase, $\beta$-glucosidase, $\alpha$-glucosidase, $\alpha$-galactosidase, acid phosphatase, leucine arylamidase, valine arylamidase, cystine arylamidase, naphthol-AS-BI-phosphohydrolase and glucosyltransferase are produced. Arginine dihydrolase, $\beta$-glucuronidase, alkaline phosphatase, $\beta$-galactosidase and $N$-acetyl- $\beta$-glucosaminidase are not produced. Voges-Proskauer test is positive. Hippurate hydrolysis test is negative. Resistant to bacitracin. An adhesive, insoluble glucan is produced from sucrose. The bacterium is cariogenic when monoassociated with specific pathogen-free rats. The serotype is type $d$. The DNA G+C content of the type strain is $43 \mathrm{~mol} \%$.

The type strain, NUM $1001^{\mathrm{T}} \quad\left(=\mathrm{JCM} \quad 14035^{\mathrm{T}}=\mathrm{DSM}\right.$ $18307^{\mathrm{T}}$ ), was isolated from clinical specimens from the oral cavities of pigs.

\section{Acknowledgements}

We are grateful to Professor Dr Hans Trüper for suggesting the species name. This study was supported, in part, by a grant from the Ministry of Education, Culture, Sports, Science, and Technology for the promotion of multidisciplinary research projects (2003). 


\section{References}

Beighton, D., Russell, R. R. B. \& Hayday, H. (1981). The isolation and characterization of Streptococcus mutans serotype $h$ from dental plaque of monkeys (Macaca fascicularis). J Gen Microbiol 124, 271-279.

Collins, M. D., Lundstrom, T., Welinder-Olsson, C., Hansson, I., Wattle, O., Hudson, R. A. \& Falsen, E. (2004). Streptococcus devriesei sp. nov., from equine teeth. Syst Appl Microbiol 27, 146-150.

Ezaki, T., Hashimoto, Y. \& Yabuuchi, E. (1989). Fluorometric deoxyribonucleic acid-deoxyribonucleic acid hybridization in microdilution wells as an alternative to membrane filter hybridization in which radioisotopes are used to determine genetic relatedness among bacterial strains. Int J Syst Bacteriol 39, 224-229.

Hamada, S. \& Slade, H. D. (1980). Biology, immunology, and cariogenicity of Streptococcus mutans. Microbiol Rev 44, 331-384.

Hirasawa, M. \& Takada, K. (1994). Porphyromonas gingivicanis sp. nov. and Porphyromonas crevioricanis sp. nov., isolated from beagles. Int J Syst Bacteriol 44, 637-640.

Hirasawa, M., Kiyono, H., Shiota, T., Michalek, S. M. \& McGhee, J. R. (1980). Virulence of Streptococcus mutans: immunochemical characterization of a serotype- $g$-defective mutant (C307). Infect Immun 27, 697-699.
Kimura, M. (1980). A simple method for estimating evolutionary rates of base substitutions through comparative studies of nucleotide sequences. J Mol Evol 16, 111-120.

Saitou, N. \& Nei, M. (1987). The neighbor-joining method: a new method for reconstructing phylogenetic trees. Mol Biol Evol 4, 406-425.

Shinoda, Y., Kato, N. \& Morita, N. (2000). Phylogenetic analysis of a bacterium by sequencing its $16 \mathrm{~S}$ ribosomal RNA gene. Shimazu Hyouron 57, 121-132 (in Japanese, with English abstract).

Takada, K., Wyszomirska, J. \& Shiota, T. (1984). Serological characterization of Streptococcus mutans serotype polysaccharide $g$ and its different molecular weight forms. Infect Immun 45, 464-469.

Thompson, J. D., Higgins, D. G. \& Gibson, T. J. (1994). ClUSTAL W: improving the sensitivity of progressive multiple sequence alignment through sequence weighting, position-specific gap penalties and weight matrix choice. Nucleic Acids Res 22, 4673-4680.

Whiley, R. A. \& Beighton, D. (1998). Current classification of the oral streptococci. Oral Microbiol Immunol 13, 195-216.

Whiley, R. A., Russell, R. R. B., Hardie, J. M. \& Beighton, D. (1988). Streptococcus downei sp. nov. for strains previously described as Streptococcus mutans serotype h. Int J Syst Bacteriol 38, 25-29. 